\title{
EFEITO DE PRÁTICAS CULTURAIS SOBRE O RENDIMENTO E OUTRAS CARACTERÍSTICAS AGRONÔMICAS DE TRIGO ( $\left.{ }^{1}\right)$
}

\author{
HENRIQUE PEREIRA DOS SANTOS $\left({ }^{2 *}\right)$; JULIO CESAR BARRENECHE LHAMBY \\ $\left({ }^{2}\right)$; SILVIO TULIO SPERA $\left({ }^{2}\right)$; ALEXANDRE ÁVILA $\left({ }^{3}\right)$
}

\begin{abstract}
RESUMO
O objetivo deste trabalho foi avaliar os efeitos de práticas culturais sobre o rendimento de grãos e algumas características agronômicas de plantas de trigo. Foram comparados quatro sistemas de manejo de solo, a saber: 1) plantio direto; 2) cultivo mínimo; 3) preparo convencional de solo com arado de discos mais grade de discos e 4) preparo convencional de solo com arado de aivecas mais grade de discos, e três sistemas de rotação de culturas: sistema I (trigo/soja), sistema II (trigo/soja e ervilhaca/milho ou sorgo) e sistema III (trigo/soja, aveia branca/soja e ervilhaca/milho ou sorgo). O delineamento experimental foi em blocos ao acaso, com parcelas subdivididas e três repetições. A parcela principal foi constituída pelos sistemas de manejo de solo, e as subparcelas, pelos sistemas de rotação de culturas. $\mathrm{O}$ rendimento de grãos e a altura de plantas de trigo cultivadas sob plantio direto e sob cultivo mínimo foram superiores ao trigo cultivado sob preparo convencional de solo com arado de discos e arado de aivecas. A maior massa de mil grãos de trigo ocorreu no plantio direto. A rotação de culturas foi eficiente na redução de doenças do sistema radicular, resultando em aumento do rendimento de grãos de trigo. $\mathrm{O}$ menor rendimento de grãos, massa de grãos, massa de mil grãos e peso do hectolitro ocorreu quando trigo foi cultivado em monocultura (trigo/soja).
\end{abstract}

Palavras-chave: sucessão de culturas, preparo convencional de solo, cultivo mínimo, plantio direto, doenças radiculares.

\section{ABSTRACT \\ EFFECT OF CULTURAL PRACTICES ON YIELD ANDAGRONOMIC CHARACTERISTICS OF WHEAT}

The effects of soil management systems and winter crop rotation on wheat yield and root diseases were assessed. Four soil management systems: 1) no-tillage; 2) minimum tillage;3) conventional tillage using a disk plow plus disk harrow and 4) conventional tillage using a moldboard plow plus disk harrow, and three crop rotation systems [system I (wheat/soybean), system II (wheat/soybean and common vetch/ corn or sorghum), and system III (wheat/soybean, white oats/soybean, and common vetch/corn or sorghum)] were compared. A randomized block experimental design, whereas split-plots and three replicates, was used. The main plots were formed by the soil management systems, while the split-plots consisted of crop rotation systems. Yield and plant height of wheat grown under no-tillage and minimum tillage was higher than the yield of wheat grown under conventional soil tillage using either disk plow or moldboard plow. Weight of 1,000 kernels was higher in the no-tillage. Crop rotation was efficient in reducing root diseases and in increasing wheat yield. The lowest wheat yield, grain weight/plant, weight of 1,000 kernels and test weight $(\mathrm{g} / \mathrm{hl})$ were obtained in monoculture (wheat/soybean).

Key words: crop succession, conventional tillage, minimum tillage, no-tillage, root diseases.

( $\left.{ }^{1}\right)$ Recebido para publicação em 4 de outubro de 2005 e aceito em 15 de julho de 2006.

$\left(^{2}\right)$ Embrapa Trigo, Caixa Postal 451,99001-970 Passo Fundo (RS). E-mail: hpsantos@cnpt.embrapa.br; julio@cnpt.embrapa.br; spera@cnpt.embrapa.br. *Autor correspondente.

$\left({ }^{3}\right)$ Bolsa de Produtividade em Pesquisa do CNPq. 


\section{INTRODUÇÃO}

Os diferentes modelos de preparo de solo podem afetar o rendimento de culturas e as características edáficas dos solos. A degradação da estrutura do solo pelo manejo inadequado pode afetar o desenvolvimento de plantas. O manejo inadequado, como por exemplo, o preparo convencional, tem sido apontado como um dos principais indicadores de degradação de solo e causa de decréscimo do rendimento das culturas. A formação de camada compactada pode ser conseqüência da intensidade de revolvimento de solo ou trânsito de máquinas, tipo de equipamento, dos sistemas de manejo de solo, da presença de resíduos vegetais e das condições hídricas do momento de preparo (STONE e SiLveira, 2001).

Para minimizar a degradação do solo e tornar viável o cultivo das espécies, indica-se o manejo conservacionista que demanda menor revolvimento de solo possível, aliado à manutenção da cobertura com palha. Esses sistemas, por sua vez, podem afetar positivamente as caraterísticas químicas, físicas e biológicas do solo com reflexo no rendimento de grãos das espécies (DA Ros et al., 1997; Franchini et al., 2000). Dessa forma, existem relativamente poucos trabalhos de longa duração, envolvendo espécies tanto de inverno como de verão, manejados sob diferentes sistemas de rotação de culturas (HERNÁNZ, et al., 1995; FONTANELI et al., 2000). As informações relativas aos componentes do rendimento de espécies sob sistemas de manejo de solo são muitos escassas na literatura.

Como exemplo de trabalho sobre sistemas de manejo do solo destaca-se o de Ruedell (1995), em Cruz Alta (RS), no qual verificou que trigo foi a espécie com menor resposta ao tipo de manejo de solo. Em trigo cultivado sob plantio direto, porém, houve rendimento de grãos mais elevado do que sob preparo convencional de solo na maioria dos anos. Para rotação de culturas, salienta-se os trabalhos de Ruedell (1995) e de SAntos et al. (1996; 1998). De acordo com esses mesmos autores, a rotação de culturas permite produzir e estabilizar o rendimento de grãos pela diversificação de espécies.

Ledinghan (1961), no Canadá, verificou em monocultura de trigo valores mais elevados de severidade de podridão-comum, em comparação a um inverno, a dois invernos, a três invernos e a cinco invernos sem esse cereal. SLOPE et al. (1973), na Inglaterra, observaram diferentes valores de severidade do mal-do-pé entre monocultura e dois invernos sem trigo. SAntos et al. (1996), em Guarapuava (PR), constataram que o menor rendimento de grãos e os valores mais elevados de severidade do mal-do-pé e da podridão-comum, ocorreram na monocultura de trigo, sob plantio direto, quando comparados a um inverno, a dois invernos ou a três invernos sem trigo.
SLOPE et al. (1973), observaram também em monocultura de trigo menor rendimento de grãos, em relação a dois invernos sem trigo, concordando com StURZ e Bernier (1989), no Canadá. Verificaram menor rendimento de grãos na monocultura de trigo, em relação a um inverno sem esse cereal, alternado com colza ou com linho.

O presente trabalho teve por objetivo avaliar os efeitos de sistemas de manejo do solo e de rotação/ sucessão de culturas no rendimento de grãos e outras características agronômicas de trigo.

\section{MATERIAL E MÉTODOS}

O experimento foi instalado na Embrapa Trigo, no município de Passo Fundo (RS), desde abril de 1986, em solo classificado como Latossolo Vermelho Distrófico típico (STRECK et al., 2002). Os resultados desse trabalho são os de 1998 a 2002.

Foi usado delineamento experimental de blocos ao acaso, com parcelas subdivididas e três repetições. A parcela principal foi constituída pelos sistemas de manejo de solo, e as subparcelas, pelos sistemas de rotação de culturas. A parcela principal media $360 \mathrm{~m} 2$ (4 m de largura por $90 \mathrm{~m}$ de comprimento), e a subparcela, $40 \mathrm{~m} 2$ (4 m de largura por $10 \mathrm{~m}$ de comprimento). Os tratamentos foram constituídos por quatro sistemas de manejo de solo: 1) plantio direto; 2 ) preparo de solo com implemento cultivo mínimo; 3 ) preparo convencional de solo com arado de discos mais grade de discos e 4) preparo convencional de solo com arado de aivecas mais grade de discos, e por três sistemas de rotação de culturas: sistema I (trigo/soja), sistema II (trigo/soja e ervilhaca/milho ou sorgo) e sistema III (trigo/soja, aveia branca/soja e ervilhaca/milho ou sorgo). As cultivares de trigo usadas foram Embrapa 16, em 1998, cultivar BR-49, em 1999 e cultivar BR-179, de 2000 a 2002. À medida que as cultivares perderam suas características foram substituídas por novos genótipos de trigo.

Em novembro de 1985, antes da instalação do experimento, foram realizadas a descompactação do solo e a correção da acidez com calcário, de acordo com os resultados da análise de solo da área experimental. As amostragens de solo, para determinação dos teores de nutrientes e do nível de matéria orgânica, foram realizadas anualmente em todas as parcelas, após a colheita das culturas de verão na profundidade de $0-20 \mathrm{~cm}$.

A semeadura, o controle de plantas daninhas e os tratamentos fitossanitários foram realizados conforme indicação para cada cultura, e a colheita de grãos foi efetuada com colhedora especial para 
parcelas experimentais. Foram efetuadas as seguintes determinações: população inicial, população final, peso do hectolitro, altura de plantas, rendimento de grãos (com umidade corrigida para 13\%), massa de mil grãos e componentes do rendimento de trigo (número de espigas, número de espiguetas e massa de grãos por planta). Os componentes do rendimento foram determinados a partir da coleta, ao acaso por parcela, de 20 espigas de trigo.

A avaliação do grau de severidade de doenças do sistema radicular de trigo (mal-do-pé, causado por Gaeumannomyces graminis var. tritici, e podridãocomum, causada por Bipolaris sorokiniana) foi realizada de acordo com o método descrito por ReIS et al. (1985). Os dados originais foram transformados em arcoseno $\sqrt{x}$ para análise da severidade de doenças do sistema radicular.
Foi efetuada análise de variância do rendimento de grãos, de algumas características e da severidade de doenças do sistema radicular de trigo (dentro de cada ano e na média conjunta dos anos de 1998 a 2002). Considerou-se o efeito tratamento (diferentes sistemas de manejos de solo e sistemas de rotação de culturas) como fixo, e o efeito ano, como aleatório. As médias foram comparadas entre si, pelo teste de Duncan, a $5 \%$ de probabilidade, utilizando-se o pacote estatístico SAS versão 8.2 (STATISTICAL, 2003).

Os valores médios - referentes aos meses de junho a outubro, da normal (1961 a 1990) e dos anos 1998 a 2002 - da precipitação pluvial, das temperaturas (mínima, média e máxima) e da unidade relativa registrados em Passo Fundo, são apresentados na tabela 1.

Tabela 1. Dados relativos à precipitação pluvial, às temperaturas mínima (mín), média (méd) e máxima (máx) e à umidade relativa, da normal (1961 a 1990) e dos anos de 1998 a 2002. Passo Fundo (RS)

\begin{tabular}{|c|c|c|c|c|c|c|}
\hline \multirow{2}{*}{ Ano } & \multicolumn{5}{|c|}{ Mês } & \multirow{2}{*}{ Acumulada } \\
\hline & Junho & Julho & Agosto & Setembro & Outubro & \\
\hline & \multicolumn{5}{|c|}{ Precipitação pluvial (mm) } & Total \\
\hline 1991 a 1990 & 129 & 153 & 166 & 207 & 167 & 822 \\
\hline 1998 & 83 & 191 & 257 & 204 & 119 & 854 \\
\hline 1999 & 94 & 177 & 19 & 150 & 177 & 617 \\
\hline 2000 & 206 & 148 & 84 & 169 & 339 & 946 \\
\hline 2001 & 107 & 96 & 28 & 240 & 276 & 747 \\
\hline \multirow[t]{2}{*}{2002} & 242 & 146 & 234 & 254 & 372 & 1.248 \\
\hline & \multicolumn{5}{|c|}{ Temperatura $\left({ }^{\circ} \mathrm{C}\right)$} & Média \\
\hline 1961 a 1990 mín & 8,9 & 8,9 & 9,9 & 11,0 & 12,9 & 10,3 \\
\hline méd & 12,7 & 12,8 & 14,0 & 14,8 & 17,7 & 14,4 \\
\hline máx & 18,4 & 18,5 & 19,9 & 21,2 & 23,8 & 20,4 \\
\hline 1998 mín & 8,5 & 10,5 & 11,2 & 10,7 & 13,7 & 10,9 \\
\hline méd & 12,3 & 13,8 & 14,1 & 14,3 & 18,0 & 14,5 \\
\hline máx & 18,3 & 19,1 & 18,7 & 19,0 & 24,2 & 19,9 \\
\hline 1999 mín & 8,6 & 8,4 & 8,5 & 11,5 & 12,1 & 9,8 \\
\hline méd & 12,0 & 11,8 & 14,0 & 16,0 & 16,2 & 14,0 \\
\hline máx & 17,5 & 16,7 & 21,1 & 22,2 & 21,3 & 19,8 \\
\hline 2000 mín & 11,3 & 5,1 & 9,1 & 10,6 & 14,9 & 10,2 \\
\hline méd & 14,4 & 9,8 & 13,8 & 15,0 & 18,8 & 14,4 \\
\hline máx & 19,5 & 16,0 & 20,3 & 20,7 & 24,5 & 20,2 \\
\hline 2001 mín & 10,1 & 9,8 & 12,4 & 12,0 & 13,9 & 11,6 \\
\hline méd & 13,6 & 13,8 & 16,6 & 15,7 & 18,6 & 15,7 \\
\hline máx & 19,2 & 19,8 & 22,4 & 20,2 & 24,7 & 21,3 \\
\hline 2002 mín & 9,3 & 8,6 & 11,3 & 9,1 & 14,8 & 10,6 \\
\hline méd & 13,2 & 12,4 & 15,2 & 14,1 & 18,8 & 14,7 \\
\hline \multirow[t]{2}{*}{ máx } & 18,6 & 18,2 & 20,4 & 20,0 & 24,1 & 20,2 \\
\hline & \multicolumn{5}{|c|}{ Umidade relativa $(\%)$} & Média \\
\hline 1961 a 1990 & 82 & 81 & 79 & 78 & 74 & 79 \\
\hline 1998 & 76 & 80 & 84 & 80 & 73 & 79 \\
\hline 1999 & 80 & 81 & 66 & 68 & 71 & 73 \\
\hline 2000 & 79 & 70 & 67 & 74 & 76 & 73 \\
\hline 2001 & 78 & 78 & 73 & 78 & 58 & 73 \\
\hline 2002 & 82 & 81 & 78 & 73 & 81 & 79 \\
\hline
\end{tabular}




\section{RESULTADOS E DISCUSSÃO}

A análise conjunta dos resultados para rendimento de grãos, população inicial, população final, número de espigas, número de espiguetas, massa de grãos, massa de mil grãos, peso do hectolitro, altura de planta e severidade de doenças do sistema radicular de trigo, no período de 1998 a 2002 foi significante para o fator o ano, indicando ser essas características afetadas por variações climáticas ocorridas entre os anos (Tabela 2). Houve ainda diferença significativa entre as médias para rendimento de grãos, massa de grãos por planta, massa de mil grãos, peso do hectolitro, altura de plantas e severidade de doenças do sistema radicular de trigo para os seguintes fatores: sistemas de manejo de solo, sistemas de rotação de culturas e interação ano versus sistemas derotação de culturas. Além disso, o rendimento de grãos, massa de mil grãos e altura de planta de trigo diferiram para interação sistemas de manejo de solo versus sistemas de rotação de culturas. Resultados concordantes para ano, para sistemas de manejo de solo, sistemas de rotação de culturas, para interação de sistemas de manejo de solo versus rotação de culturas foram relatados por LANGDALE et al. (1990), Nesse caso, houve aumento de rendimento de grãos, em decorrência da rotação de culturas, principalmente nas espécies de verão.

Tabela 2. Significância do teste F quanto a dez características agronômicas de trigo, semeado de 1998 a 2002 . Passo Fundo (RS)

\begin{tabular}{|c|c|c|c|c|c|c|c|}
\hline Característica agronômica & $\begin{array}{c}\text { Ano } \\
x\end{array}$ & $\begin{array}{c}\text { Manejo } \\
\mathrm{x}\end{array}$ & $\begin{array}{c}\text { Rotação } \\
x\end{array}$ & $\begin{array}{c}\text { Ano x } \\
\text { Manejo }\end{array}$ & $\begin{array}{c}\text { Ano x } \\
\text { Rotação }\end{array}$ & $\begin{array}{l}\text { Manejo x } \\
\text { Rotação }\end{array}$ & $\begin{array}{c}\text { Ano x Manejo } \\
\text { XRotação }\end{array}$ \\
\hline Rendimento de grãos $\left(\mathrm{kg} \mathrm{ha}^{-1}\right)$ & ** & ** & ** & ns & ** & ** & ns \\
\hline População inicial de plantas $\left(\mathrm{m}^{2}\right)$ & $* *$ & ns & $\mathrm{ns}$ & ns & $\mathrm{ns}$ & ns & $\mathrm{ns}$ \\
\hline População final de plantas $\left(\mathrm{m}^{2}\right)$ & $* *$ & $* *$ & ns & $* *$ & ns & ns & ns \\
\hline Número de espiguetas/planta & $* *$ & $\mathrm{~ns}$ & ns & $* *$ & ns & $\mathrm{ns}$ & ns \\
\hline Número de grãos/planta & $* *$ & $\mathrm{~ns}$ & * & ns & $* *$ & ns & $\mathrm{ns}$ \\
\hline Massa de grãos/planta (g) & $* *$ & * & ** & * & ** & ns & ns \\
\hline Massa de mil grãos (g) & $* *$ & ** & ** & $* *$ & $* *$ & * & $\mathrm{ns}$ \\
\hline Peso do hectolitro $\left(\mathrm{kg} \mathrm{hl}^{-1}\right)$ & $* *$ & ** & ** & ** & ** & ns & ns \\
\hline Altura de plantas $(\mathrm{cm})$ & $* *$ & $* *$ & $* *$ & ** & ns & * & ns \\
\hline Severidade de doenças (\%) & $* *$ & * & $* *$ & ns & $* *$ & ns & ns \\
\hline
\end{tabular}

ns: não significativo; *: nível de significância de 5\%; e **: nível de significância de $1 \%$.

No rendimento de grãos, na massa de grãos por planta, na massa de mil grãos, no peso do hectolitro e na altura de plantas de trigo, em todos anos estudados e na média desses anos (Tabelas 3 e 4), houve diferenças significativas entre sistemas de manejo de solo. O rendimento de grãos mais elevado ocorreu no sistema plantio direto e no cultivo mínimo, em comparação com preparos convencionais de solo com arado de discos ou com arado de aivecas. Esse fato, já havia ocorrido na primeira avaliação desse experimento referente ao período de 1988 a 1997 (SANTOS et al., 2000). Essas diferenças, provavelmente, podem ser atribuídas a deficiência hídrica em alguma fase crítica de desenvolvimento da cultura e ao acúmulo de nutrientes e de matéria orgânica na camada superficial do solo (SANTOS e TOMM, 2003). No caso do plantio direto, também, pode ser explicado, em parte, pela massa de grãos por planta e massa de mil grãos de trigo, que foram mais elevados em relação aos sistemas de preparos convencionais de solo (tabelas 3 e 4). Além disso, os sistemas conservacionistas (plantio direto e cultivo mínimo) favoreceram o peso do hectolitro e a altura de plantas de trigo mais elevados do que o preparo convencional de solo com arado de discos (Tabela 4).

O baixo rendimento de grãos de trigo em todos sistemas de manejo, em 1998, foi atribuído ao intenso ataque de ferrugem da folha (Puccinia recondita f.sp. tritici) e de mancha salpicada da folha (Septoria tritici), enquanto, em 2002, foi devido à alta incidência de giberela (Gibberela zeae), uma vez que o excesso de precipitação pluvial (Tabela 2), em ambos os anos, dificultou o controle dessas doenças.

Deve-se considerar que as espécies, de maneira geral, possuem um estádio de desenvolvimento no qual a deficiência hídrica causa maior redução no rendimento de grãos. No caso de trigo, ocorre do estádio de folha-bandeira ao estádio de antese, que, nas condições da Região Sul brasileira, na maioria das 
vezes, manifesta-se no fim de agosto (RODRIGUEs et al., 1998). A quantidade de precipitação pluvial requerida para a cultura de trigo completar seu ciclo é de aproximadamente $322 \mathrm{~mm}$ (Matzenauer, 1992).Entretanto, na região de Passo Fundo ( RS), a precipitação pluvial normal para o período é de 822 $\mathrm{mm}$ (BRASIL, 1992). No decorrer dos anos de desenvolvimento deste trabalho, a precipitação pluvial foi baixa (Tabela 1), somente em agosto de 1999 (19 $\mathrm{mm}$ ). Na maioria desses anos ocorreu precipitação pluvial abaixo da normal, em junho, mês de estabelecimento da cultura de trigo na região de Passo Fundo (RS), conforme tabela 2. Esse fato pode explicar, em parte, a diferença em rendimento de grãos entre sistemas conservacionistas de manejo de solo e sistemas convencionais de preparo de solo. O sistema conservacionista de manejo tem condições de armazenar mais água para ser usada nos períodos críticos do desenvolvimento de trigo.

Porto (1980), ao desenvolver estudo com sistemas de manejo de solo, em Passo Fundo ( RS), verificou que trigo cultivado sob sistema plantio direto rendeu mais do que sob preparo convencional de solo. Ruedell (1995), em Cruz Alta (RS), verificou que trigo foi a espécie que recebeu menor influência do sistema de manejo de solo. De nove anos estudados, em oito anos, no sistema plantio direto houve rendimento de grãos mais elevado do que no preparo convencional de solo.

A severidade de doenças do sistema radicular de trigo (mal-do-pé e podridão-comum), em 1998 e 2001, e na média dos anos, diferiu significativamente entre sistemas de manejo de solo (Tabela 3). Constataram-se valores mais elevados no sistema plantio direto e no cultivo mínimo, em relação ao preparo convencional de solo com arado de discos. Na primeira avaliação desse trabalho, de 1988 a 1997, a hipótese aceitável para esclarecer a diferença entre os sistemas conservacionistas de manejo de solo e os sistemas de preparo convencional de solo, ou seja, trigo cultivado sob cultivo mínimo, sob plantio direto, sob preparo convencional com arado de discos e com severidade das doenças do sistema radicular mais elevada do que em trigo cultivado sob preparo convencional com arado de aivecas, seria a intensidade do revolvimento do solo provocado pelas aivecas, que teriam enterrado com maior eficiência os propágulos desse complexo de doenças fitopatológicas (SANTOS et al., 2000).

Tabela 3. Efeito de sistemas de manejo de solo na severidade de doenças do sistema radicular, no rendimento de grãos e na massa de grãos por planta de trigo, em 1998, cultivar Embrapa 16, em 1999, cultivar BR-49 e de 2000 a 2002, cultivar BR-179. Passo Fundo (RS)

\begin{tabular}{|c|c|c|c|c|c|}
\hline \multirow[b]{2}{*}{ Ano } & \multicolumn{4}{|c|}{ Manejo de solo } & \multirow{2}{*}{ *Média } \\
\hline & PD & PCD & PCA & PM & \\
\hline \multicolumn{6}{|c|}{ Severidade de doenças do sistema radicular de trigo (\%) } \\
\hline 1998 & $26 \mathrm{~A} \mathrm{a}$ & $21 \mathrm{~B}$ a & $23 \mathrm{~A} \mathrm{ba}$ & $25 \mathrm{~A} \mathrm{a}$ & $24 \mathrm{a}$ \\
\hline 1999 & $8 \mathrm{Ac}$ & $10 \mathrm{~A} \mathrm{C}$ & $7 \mathrm{~A} \mathrm{c}$ & $8 \mathrm{Ac}$ & $8 d$ \\
\hline 2000 & $10 \mathrm{~A} \mathrm{C}$ & $10 \mathrm{~A} \mathrm{C}$ & $11 \mathrm{~A} \mathrm{C}$ & $10 \mathrm{~A} \mathrm{C}$ & $10 \mathrm{c}$ \\
\hline 2001 & $10 \mathrm{~A} \mathrm{C}$ & $6 \mathrm{~B} \mathrm{C}$ & $8 \mathrm{~A} \mathrm{bc}$ & $12 \mathrm{~A} \mathrm{~b}$ & $10 \mathrm{~cd}$ \\
\hline 2002 & $17 \mathrm{~A} \mathrm{~b}$ & $15 \mathrm{~A} \mathrm{~b}$ & $18 \mathrm{~A} \mathrm{~b}$ & $16 \mathrm{~A} \mathrm{~b}$ & $25 \mathrm{bc}$ \\
\hline Média & $14 \mathrm{~A}$ & $12 \mathrm{~B}$ & $13 \mathrm{AB}$ & $14 \mathrm{~A}$ & 15 \\
\hline \multicolumn{6}{|c|}{ Rendimento de grãos de trigo $\left(\mathrm{kg} \mathrm{ha}^{-1}\right)$} \\
\hline 1998 & $1.362 \mathrm{~A} \mathrm{~d}$ & $1.001 \mathrm{~B} \mathrm{~d}$ & $803 \mathrm{C} \mathrm{d}$ & $1.305 \mathrm{~A} \mathrm{~d}$ & $1.119 \mathrm{~d}$ \\
\hline 1999 & $3.632 \mathrm{~A} \mathrm{a}$ & $3.393 \mathrm{~B} \mathrm{a}$ & $3.382 \mathrm{~B} \mathrm{a}$ & $3.664 \mathrm{~A} \mathrm{a}$ & $3.518 \mathrm{a}$ \\
\hline 2000 & $2.564 \mathrm{~A} \mathrm{~b}$ & $2.354 \mathrm{~B} \mathrm{~b}$ & $2.282 \mathrm{~B} \mathrm{~b}$ & $2.543 \mathrm{~A} \mathrm{~b}$ & $2.436 \mathrm{~b}$ \\
\hline 2001 & $2.011 \mathrm{~A} \mathrm{c}$ & $1.670 \mathrm{~B} \mathrm{c}$ & $1.539 \mathrm{~B} \mathrm{c}$ & $2.038 \mathrm{~A} \mathrm{c}$ & $1.814 \mathrm{c}$ \\
\hline 2002 & $1.880 \mathrm{~A} \mathrm{C}$ & $1.662 \mathrm{~B} \mathrm{C}$ & $1.642 \mathrm{~B} \mathrm{C}$ & $1.874 \mathrm{~A} \mathrm{C}$ & $1.764 \mathrm{c}$ \\
\hline Média & $2.290 \mathrm{~A}$ & $2.016 \mathrm{~B}$ & $1.930 \mathrm{C}$ & $2.285 \mathrm{~A}$ & 2.130 \\
\hline \multicolumn{6}{|c|}{ Massa de grãos por planta (g) } \\
\hline 1998 & $0,83 \mathrm{~A} \mathrm{c}$ & $0,68 \mathrm{~B} \mathrm{c}$ & $0,60 \mathrm{~B} \mathrm{~d}$ & $0,82 \mathrm{~A} \mathrm{~d}$ & $0,73 \mathrm{~d}$ \\
\hline 1999 & $1,33 \mathrm{~A} \mathrm{a}$ & $1,37 \mathrm{~A} \mathrm{a}$ & $1,39 \mathrm{~A} \mathrm{a}$ & $1,40 \mathrm{~A} \mathrm{a}$ & $1,37 \mathrm{a}$ \\
\hline 2000 & $1,07 \mathrm{~A} \mathrm{~b}$ & $1,03 \mathrm{~A} \mathrm{~b}$ & $0,96 \mathrm{AB} b$ & $0,90 \mathrm{~B} \mathrm{c}$ & $0,99 \mathrm{bc}$ \\
\hline 2001 & $1,00 \mathrm{~A} \mathrm{~b}$ & $0,90 \mathrm{~B} \mathrm{~b}$ & $0,88 \mathrm{~B} \mathrm{c}$ & $1,06 \mathrm{~A} \mathrm{~b}$ & $0,96 \mathrm{c}$ \\
\hline 2002 & $1,08 \mathrm{~A} \mathrm{~b}$ & $1,01 \mathrm{~A} \mathrm{~b}$ & $1,03 \mathrm{~A} \mathrm{~b}$ & $1,02 \mathrm{~B} \mathrm{~b}$ & $1,04 \mathrm{~b}$ \\
\hline Média & $1,06 \mathrm{~A}$ & $0,99 \mathrm{BC}$ & $0,97 \mathrm{C}$ & $1,04 \mathrm{AB}$ & 1,02 \\
\hline
\end{tabular}

PD: plantio direto; PCD: preparo convencional de solo com arado de discos; PCA: preparo convencional de solo com arado de aivecas; e PM: cultivo mínimo.

*Médias seguidas da mesma letra, minúscula na vertical e maiúscula na horizontal, não apresentam diferenças significativas, a 5\% de probabilidade, pelo teste de Duncan. 
Tabela 4. Efeito de sistemas de manejo de solo na massa de mil grãos, no peso do hectolitro e na altura de plantas de trigo, em 1998, cultivar Embrapa 16, em 1999, cultivar BR-49 e de 2000 a 2002, cultivar BR-179. Passo Fundo (RS)

\begin{tabular}{|c|c|c|c|c|c|}
\hline \multirow{2}{*}{ Ano } & \multicolumn{4}{|c|}{ Manejo de solo } & \multirow{2}{*}{ *Média } \\
\hline & PD & PCD & PCA & PM & \\
\hline \multicolumn{6}{|c|}{ Massa de mil grãos $(\mathrm{g})$} \\
\hline 1998 & $22,61 \mathrm{~A} \mathrm{e}$ & $21,23 \mathrm{~B}$ e & $19,44 \mathrm{C} \mathrm{e}$ & $21,87 \mathrm{~A} \mathrm{e}$ & $21,28 \mathrm{e}$ \\
\hline 1999 & $36,15 \mathrm{~A}$ a & $36,56 \mathrm{~A}$ a & $36,50 \mathrm{~A} \mathrm{a}$ & $35,40 \mathrm{~A} \mathrm{a}$ & 36,15 a \\
\hline 2000 & $28,44 \mathrm{~A} \mathrm{C}$ & $26,50 \mathrm{~B}$ c- & $26,01 \mathrm{C} \mathrm{C}$ & $27,45 \mathrm{~A} \mathrm{c}$ & $27,10 \mathrm{c}$ \\
\hline 2001 & $30,61 \mathrm{~A} \mathrm{~b}$ & $28,48 \mathrm{~B} \mathrm{~b}$ & $29,28 \mathrm{~B} \mathrm{~b}$ & $30,90 \mathrm{~A} \mathrm{~b}$ & $29,82 \mathrm{~b}$ \\
\hline 2002 & $24,84 \mathrm{~A} \mathrm{~d}$ & $22,93 \mathrm{~B} \mathrm{~d}$ & $23,41 \mathrm{~B} \mathrm{~d}$ & $23,72 \mathrm{~A} \mathrm{~d}$ & $23,73 \mathrm{~d}$ \\
\hline Média & $28,53 \mathrm{~A}$ & $27,14 \mathrm{C}$ & $26,93 \mathrm{C}$ & $27,87 \mathrm{~B}$ & 27,62 \\
\hline \multicolumn{6}{|c|}{ Peso do hectolitro $\left(\mathrm{kg} \mathrm{hl}^{-1}\right)$} \\
\hline 1998 & $73 \mathrm{~A} \mathrm{~b}$ & $72 \mathrm{~A} \mathrm{~d}$ & $69 \mathrm{~B} \mathrm{~d}$ & $72 \mathrm{~A} \mathrm{c}$ & $71 \mathrm{c}$ \\
\hline 1999 & $76 \mathrm{~A} \mathrm{a}$ & $76 \mathrm{~A}$ a & $76 \mathrm{~A} \mathrm{a}$ & $75 \mathrm{~A} \mathrm{a}$ & $76 \mathrm{a}$ \\
\hline 2000 & $75 \mathrm{~A} \mathrm{a}$ & $73 \mathrm{~B} \mathrm{c}$ & $74 \mathrm{~A} \mathrm{bc}$ & $75 \mathrm{~A} \mathrm{ab}$ & $75 \mathrm{~b}$ \\
\hline 2001 & $76 \mathrm{~A} \mathrm{a}$ & $75 \mathrm{~A}$ a & $75 \mathrm{~B} \mathrm{~b}$ & $76 \mathrm{~A} \mathrm{a}$ & $76 \mathrm{a}$ \\
\hline 2002 & $76 \mathrm{~A} \mathrm{a}$ & $74 \mathrm{~B}$ b & $76 \mathrm{~A} \mathrm{a}$ & $75 \mathrm{~A} \mathrm{~b}$ & $75 \mathrm{~b}$ \\
\hline Média & $76 \mathrm{~A}$ & $74 \mathrm{BC}$ & $73 \mathrm{C}$ & $75 \mathrm{AB}$ & 75 \\
\hline \multicolumn{6}{|c|}{ Altura de plantas $(\mathrm{cm})$} \\
\hline 1998 & $90 \mathrm{~A} \mathrm{a}$ & $89 \mathrm{~B} \mathrm{~b}$ & $78 \mathrm{~B} \mathrm{c}$ & $91 \mathrm{~A} \mathrm{a}$ & $85 \mathrm{~b}$ \\
\hline 1999 & $91 \mathrm{~A} \mathrm{a}$ & $84 \mathrm{~B} \mathrm{a}$ & $83 \mathrm{~B} \mathrm{~b}$ & $90 \mathrm{~A} \mathrm{a}$ & $87 \mathrm{a}$ \\
\hline 2000 & $92 \mathrm{~A} \mathrm{a}$ & $85 \mathrm{~B} \mathrm{a}$ & $87 \mathrm{~B} \mathrm{a}$ & $88 \mathrm{~B} \mathrm{~b}$ & $88 \mathrm{a}$ \\
\hline 2001 & $80 \mathrm{~A} \mathrm{c}$ & $76 \mathrm{C} \mathrm{c}$ & $77 \mathrm{~B} \mathrm{C}$ & $80 \mathrm{Ad}$ & $78 \mathrm{c}$ \\
\hline 2002 & $86 \mathrm{~A} \mathrm{~b}$ & $83 \mathrm{~A} \mathrm{a}$ & $84 \mathrm{~A} \mathrm{a}$ & $86 \mathrm{~A} \mathrm{c}$ & $85 \mathrm{~b}$ \\
\hline Média & $88 \mathrm{~A}$ & $82 \mathrm{~B}$ & $82 \mathrm{~B}$ & $87 \mathrm{~A}$ & 85 \\
\hline
\end{tabular}

PD: plantio direto; PCD: preparo convencional de solo com arado de discos; PCA: preparo convencional de solo com arado de aivecas; e PM: cultivo mínimo.

* Médias seguidas da mesma letra, minúscula na vertical e maiúscula na horizontal, não apresentam diferenças significativas, a 5\% de probabilidade, pelo teste de Duncan.

Em todos os anos estudados e na média dos anos, o rendimento de grãos, a massa de grãos por planta, a massa de mil grãos, o peso do hectolitro e a altura de plantas de trigo cultivadas em sistemas de rotação de culturas diferiram significativamente (Tabelas 5 e 6). No sistema de rotação de culturas com dois invernos sem trigo, houve rendimento médio de grãos e altura de plantas mais elevadas do que sob monocultura e sob um inverno sem trigo. Por sua vez, os sistemas com um ou dois invernos sem trigo apresentaram massa de grãos por planta, massa de mil grãos e peso do hectolitro superior a monocultura de trigo (Tabelas 5 e 6 ). Contudo, o menor rendimento de grãos, massa de grãos por planta, massa de mil grãos, peso do hectolitro e altura de plantas de trigo ocorreram na monocultura desse cereal.

Em trigo após milho ou sorgo (com um inverno de rotação) houve rendimento de grãos intermediário entre a monocultura desse cereal e rotação de dois invernos (Tabela 5).Como nesse sistema havia um inverno de rotação, era esperado que o rendimento de grãos fosse semelhante ao de trigo com dois invernos de rotação, conforme observado em estudos com sistemas de rotação para essa espécie desenvolvidos por SANTOS et al. (1996), em Guarapuava (PR) e SANTOS et al. (1998), em Passo Fundo (RS), nos quais foram comparados vários sistemas de rotação de culturas contra estudos com a monocultura desse cereal.

SCHAFFNER e BREgANTE (1984) avaliaram os efeitos residuais de girassol, de milho, de soja e de sorgo e o crescimento e sobre o rendimento de grãos de trigo, no Uruguai. Em todos os resíduos vegetais ocorreram efeitos alelopáticos sobre o rendimento de grãos de trigo, mas o resíduo de sorgo foi o que mais afetou negativamente a cultura de trigo.

Em vários trabalhos, estuda-se o menor rendimento de grãos de trigo sob monocultura, em comparação com sistemas de rotação de culturas. SLOPE et al. (1973) constataram que na monocultura de trigo houve menor rendimento de grãos $(4.530 \mathrm{~kg}$ $\left.\mathrm{ha}^{-1}\right)$ do que em dois invernos (5.460 $\left.\mathrm{kg} \mathrm{ha}^{-1}\right)$ sem trigo. StURz e BERNIER (1989) observaram que monocultura de trigo $\left(3.179 \mathrm{~kg} \mathrm{ha}^{-1}\right)$ rendeu menos do que havia em um inverno sem esse cereal em alternância com colza $\left(4.203 \mathrm{~kg} \mathrm{ha}^{-1}\right)$ ou com linho $\left(4.076 \mathrm{~kg} \mathrm{ha}^{-1}\right)$. SANTOS et al. (1996) verificaram sob plantio direto, que o menor rendimento de grãos ocorreu na monocultura de trigo $\left(3.014 \mathrm{~kg} \mathrm{ha}^{-1}\right)$, em comparação com os sistemas de rotação com um inverno $\left(3.355 \mathrm{~kg} \mathrm{ha}^{-1}\right)$, dois invernos $\left(3.494 \mathrm{~kg} \mathrm{ha}^{-1}\right)$ e três invernos $\left(3.362 \mathrm{~kg} \mathrm{ha}^{-1}\right)$ sem trigo. Santos et al. 
(1998), em áreas sob preparo convencional de solo, no inverno, e sob plantio direto, no verão, em Passo Fundo (RS), também verificaram menor rendimento de grãos na monocultura de trigo $\left(2.238 \mathrm{~kg} \mathrm{ha}^{-1}\right)$ do que em um inverno $\left(3.502 \mathrm{~kg} \mathrm{ha}^{-1}\right)$, dois invernos (3.403 $\left.\mathrm{kg} \mathrm{ha}^{-1}\right)$, três invernos $\left(3.629 \mathrm{~kg} \mathrm{ha}^{-1}\right)$, dois invernos sem e dois com trigo (3.476 e $3.290 \mathrm{~kg} \mathrm{ha}^{-1}$ ) e três invernos sem e dois com trigo (3.557 e $3.528 \mathrm{~kg} \mathrm{ha}^{-1}$ ).

Maior valor médio de rendimento de grãos de trigo para todos os sistemas de manejo de solo e de rotação de culturas foi observado em $1999(3.518 \mathrm{~kg}$ $\left.\mathrm{ha}^{-1}\right)$ (Tabelas 3 e 5 ), enquanto o menor rendimento de grãos ocorreu em1998 (1.119 kg ha-1). O melhor rendimento de grãos de trigo ocorreu nos sistemas de manejo de solo (cultivo mínimo e plantio direto), em comparação com os sistemas de preparo convencional de solo (com arado de discos ou com arado de aivecas).

Em todos os anos estudados e na média dos anos, houve diferenças significativas na severidade de doenças do sistema radicular de trigo, decorrentes dos sistemas de rotação de culturas (Tabela 4). Os valores mais elevados de severidade do mal-do-pé e de podridão-comum de raízes, ocorreram na monocultura de trigo, em comparação com um inverno e com dois invernos sem essa gramínea, demonstrando o efeito positivo da rotação com espécies não suscetíveis.

Ledinghan (1961), no Canadá, constatou valores mais elevados de severidade da podridãocomum de raízes de trigo que ocorreram em monocultura (68\%) e em um inverno sem trigo (64\%), em comparação a dois invernos (37\%), a três invernos $(34 \%)$ e a cinco invernos $(14 \%)$ sem esse cereal. Mediante esses resultados, houve decréscimo da doença proporcionalmente ao aumento de anos de rotação de trigo. Slope et al. (1973) verificaram que a monocultura (35\%) e dois anos de rotação de culturas não suscetíveis ( $3 \%$ ) diferiram entre si para severidade do mal-do-pé. SANTOS et al. (1996) sob plantio direto, verificaram valores mais elevados de severidade de podridões de raízes de trigo em monocultura (39\%) do que em trigo cultivado em rotação de um inverno $(12 \%)$, dois invernos $(9 \%)$ e três invernos $(11 \%)$. SANTOS et al. (1998) relataram os seguintes percentuais de severidade do mal-do-pé e da podridão-comum: monocultura de trigo $(50 \%)$, um inverno $(13 \%)$, dois invernos (10\%), três invernos $(10 \%)$, dois invernos sem e dois com trigo (13\% e $16 \%$ ) e três invernos sem e dois com trigo ( $12 \%$ e $19 \%)$.

Tabela 5. Efeito de sistemas de rotação de culturas na severidade de doenças do sistema radicular, no rendimento de grãos e na massa de grãos por planta de trigo, em 1998, cultivar Embrapa 16, em 1999, cultivar BR-49 e de 2000 a 2002, cultivar BR-179. Passo Fundo (RS)

\begin{tabular}{|c|c|c|c|c|}
\hline \multirow{2}{*}{ Ano } & \multicolumn{3}{|c|}{ Sistema de rotação } & \multirow{2}{*}{ *Média } \\
\hline & Monocultura & Um inverno sem trigo & Dois invernos sem trigo & \\
\hline \multicolumn{5}{|c|}{ Severidade de doenças do sistema radicular de trigo (\%) } \\
\hline 1998 & $28 \mathrm{~A} \mathrm{a}$ & $21 \mathrm{~B}$ a & $22 \mathrm{~B}$ a & $24 \mathrm{a}$ \\
\hline 1999 & $8 \mathrm{~A} \mathrm{c}$ & $8 \mathrm{~A} \mathrm{~b}$ & 7 B d & $8 \mathrm{~d}$ \\
\hline 2000 & $13 \mathrm{~A} \mathrm{~b}$ & $9 \mathrm{~A} \mathrm{~b}$ & $9 \mathrm{~B} \mathrm{~b}$ & $10 \mathrm{c}$ \\
\hline 2001 & $16 \mathrm{~A} \mathrm{~b}$ & $6 \mathrm{~B} \mathrm{c}$ & $5 \mathrm{~B} \mathrm{~b}$ & $9 \mathrm{~cd}$ \\
\hline 2003 & $29 \mathrm{~A} \mathrm{a}$ & $12 \mathrm{~B} \mathrm{~b}$ & $8 \mathrm{C} \mathrm{b}$ & $16 \mathrm{~b}$ \\
\hline Média & $19 \mathrm{~A}$ & $11 \mathrm{~B}$ & $10 \mathrm{~B}$ & 13 \\
\hline \multicolumn{5}{|c|}{ Rendimento de grãos $\left(\mathrm{kg} \mathrm{ha}{ }^{-1}\right)$} \\
\hline 1998 & $857 \mathrm{C} \mathrm{e}$ & $1.119 \mathrm{~B} \mathrm{~d}$ & $1.377 \mathrm{~A} \mathrm{~d}$ & $1.118 \mathrm{~d}$ \\
\hline 1999 & $3.334 \mathrm{C} \mathrm{a}$ & $3.538 \mathrm{~B} \mathrm{a}$ & $3.672 \mathrm{~A} \mathrm{a}$ & $3.518 \mathrm{a}$ \\
\hline 2000 & $2.089 \mathrm{C} \mathrm{b}$ & $2.541 \mathrm{~B} \mathrm{~b}$ & $2.678 \mathrm{~A} \mathrm{~b}$ & $2.436 \mathrm{~b}$ \\
\hline 2001 & 1.612 C c & $1.817 \mathrm{~B} \mathrm{c}$ & $2.014 \mathrm{~A} \mathrm{c}$ & $1.814 \mathrm{c}$ \\
\hline 2003 & $1.446 \mathrm{C} \mathrm{d}$ & $1.824 \mathrm{~B} \mathrm{C}$ & $2.023 \mathrm{~A} \mathrm{c}$ & $1.764 \mathrm{c}$ \\
\hline Média & $1.870 \mathrm{C}$ & $2.168 \mathrm{~B}$ & $2.353 \mathrm{~A}$ & 2.130 \\
\hline \multicolumn{5}{|c|}{ Massa de grãos por planta (g) } \\
\hline 1998 & $0,62 \mathrm{~B} \mathrm{~d}$ & $0,78 \mathrm{~A} \mathrm{~d}$ & $0,80 \mathrm{~A} \mathrm{c}$ & $0,73 \mathrm{~d}$ \\
\hline 1999 & $1,39 \mathrm{~A} \mathrm{a}$ & $1,42 \mathrm{~A} \mathrm{a}$ & $1,31 \mathrm{~B} \mathrm{a}$ & $1,37 \mathrm{a}$ \\
\hline 2000 & $0,85 \mathrm{~A} \mathrm{c}$ & $1,04 \mathrm{~A} \mathrm{~b}$ & $1,08 \mathrm{~A} \mathrm{~b}$ & $0,99 \mathrm{bc}$ \\
\hline 2001 & $0,89 \mathrm{~B} \mathrm{c}$ & 0,98 A c & $1,01 \mathrm{~A} \mathrm{~b}$ & $0,96 \mathrm{c}$ \\
\hline 2003 & $0,99 \mathrm{~B} \mathrm{~b}$ & $1,11 \mathrm{~A} \mathrm{~b}$ & $1,01 \mathrm{~A} \mathrm{~b}$ & $1,04 \mathrm{~b}$ \\
\hline Média & $0,95 \mathrm{~B}$ & $1,06 \mathrm{~A}$ & $1,04 \mathrm{~A}$ & 1,02 \\
\hline
\end{tabular}

* Médias seguidas da mesma letra, minúscula na vertical e maiúscula na horizontal, não apresentam diferenças significativas, a 5\% de probabilidade, pelo teste de Duncan. 
Tabela 6. Efeito de sistemas de rotação de culturas sobre a massa de mil grãos, peso do hectolitro e altura de plantas de trigo, em 1998, cultivar Embrapa 16, em 1999, cultivar BR-49 e de 2000 a 2002, cultivar BR-179. Passo Fundo (RS)

\begin{tabular}{|c|c|c|c|c|}
\hline \multirow{2}{*}{ Ano } & \multicolumn{3}{|c|}{ Sistema de rotação } & \multirow{2}{*}{ Média } \\
\hline & Monocultura & Um inverno sem trigo & Dois invernos sem trigo & \\
\hline \multicolumn{5}{|c|}{ Massa de mil grãos (g) } \\
\hline 1998 & $19,71 \mathrm{~B} \mathrm{e}$ & $21,84 \mathrm{~A} \mathrm{e}$ & $22,31 \mathrm{~A} \mathrm{e}$ & $21,28 \mathrm{e}$ \\
\hline 1999 & $35,45 \mathrm{~B}$ a & $36,61 \mathrm{~A} \mathrm{a}$ & $36,40 \mathrm{~A} \mathrm{a}$ & $36,15 \mathrm{a}$ \\
\hline 2000 & $25,76 \mathrm{C} \mathrm{c}$ & 27,17 B c & $28,37 \mathrm{~A} \mathrm{c}$ & $27,10 \mathrm{c}$ \\
\hline 2001 & $28,45 \mathrm{~B} \mathrm{~b}$ & $30,22 \mathrm{~A} \mathrm{~b}$ & $30,78 \mathrm{~A} \mathrm{~b}$ & $29,82 \mathrm{~b}$ \\
\hline 2003 & $21,73 \mathrm{C} \mathrm{d}$ & $25,86 \mathrm{~A} \mathrm{~d}$ & $23,59 \mathrm{~B} \mathrm{~d}$ & $23,73 \mathrm{~d}$ \\
\hline Média & $26,22 \mathrm{~B}$ & $28,34 \mathrm{~A}$ & $28,29 \mathrm{~A}$ & 27,62 \\
\hline \multicolumn{5}{|c|}{ Peso do hectolitro $\left(\mathrm{kg} \mathrm{hl}^{-1}\right)$} \\
\hline 1998 & $69 \mathrm{~B} \mathrm{~d}$ & $72 \mathrm{~A} \mathrm{C}$ & $73 \mathrm{~A} \mathrm{c}$ & $71 \mathrm{c}$ \\
\hline 1999 & $76 \mathrm{~A}$ a & $76 \mathrm{~A} \mathrm{~b}$ & $76 \mathrm{~A} \mathrm{a}$ & 76 a \\
\hline 2000 & $74 \mathrm{~A} \mathrm{~b}$ & $75 \mathrm{~A} \mathrm{~b}$ & $75 \mathrm{~A} \mathrm{~b}$ & $75 \mathrm{~b}$ \\
\hline 2001 & $75 \mathrm{~B}$ a & $75 \mathrm{~B} \mathrm{~b}$ & $77 \mathrm{~A}$ a & 76 a \\
\hline 2003 & $73 \mathrm{C} \mathrm{c}$ & $77 \mathrm{~A} \mathrm{a}$ & $75 \mathrm{~B} \mathrm{~b}$ & $75 \mathrm{~b}$ \\
\hline Média & $73 \mathrm{~B}$ & $75 \mathrm{~A}$ & $75 \mathrm{~A}$ & 75 \\
\hline \multicolumn{5}{|c|}{ Altura de planta $(\mathrm{cm})$} \\
\hline 1998 & $81 \mathrm{~B} \mathrm{~b}$ & $87 \mathrm{~A} a b$ & $87 \mathrm{~A} \mathrm{a}$ & $85 \mathrm{~b}$ \\
\hline 1999 & $86 \mathrm{~A}$ a & $88 \mathrm{~A} \mathrm{a}$ & $88 \mathrm{~A} \mathrm{a}$ & $87 \mathrm{a}$ \\
\hline 2000 & $85 \mathrm{~B}$ a & $89 \mathrm{~A} \mathrm{a}$ & $90 \mathrm{~A} \mathrm{a}$ & $88 \mathrm{a}$ \\
\hline 2001 & $76 \mathrm{~B} \mathrm{c}$ & 77 B c & $82 \mathrm{~A} \mathrm{~b}$ & $78 \mathrm{c}$ \\
\hline 2003 & $81 \mathrm{~B} \mathrm{~b}$ & $86 \mathrm{~A} \mathrm{~b}$ & $88 \mathrm{~A} \mathrm{a}$ & $85 \mathrm{~b}$ \\
\hline Média & $82 \mathrm{C}$ & $85 \mathrm{~B}$ & $87 \mathrm{~A}$ & 85 \\
\hline
\end{tabular}

Médias seguidas da mesma letra, minúscula na vertical e maiúscula na horizontal, não apresentam diferenças significativas, a $5 \%$ de probabilidade, pelo teste de Duncan.

O valor mais elevado de severidade de doenças do sistema radicular de trigo, em todos os sistemas manejo ou de rotação de culturas, foi verificado em 1998 (24\%) (tabelas 3 e 5). Deve ser considerado que os valores obtidos para severidade de doenças do sistema radicular de trigo, ao longo desses anos, mantiveram-se em limiar relativamente baixo, mesmo na monocultura de trigo (19\%).

\section{CONCLUSÕES}

1. Trigo cultivado em plantio direto e cultivo mínimo tem maior rendimento de grãos, massa de mil grãos e altura de plantas do que trigo cultivado sob preparo convencional de solo com arado de discos e com arado de aivecas.

2. A rotação de culturas com dois invernos propicia maior rendimento de grãos e altura de plantas de trigo, em relação à monocultura e a um inverno sem trigo.

3. A severidade de doenças do sistema radicular é maior em monocultura do que em rotação de culturas por um ou dois invernos sem trigo.
4. A menor massa de grãos, massa de mil grãos e altura de plantas manifesta-se na monocultura, em comparação com a rotação de um ou dois invernos de trigo.

\section{REFERÊNCIAS}

BRASIL. Ministério da Agricultura e da Reforma Agrária. Departamento Nacional de Meteorologia.Normais climatológicas (1961-1990). Brasília, 1992.84p.

DA ROS, C.O.; SECCO, D.; FIORIN, J.E.; PETRERE, C.; CADORE, M.A.; PASA, L.Manejo do solo a partir de campo nativo: efeito sobre a forma e estabilidade da estrutura ao final de cinco anos. Revista Brasileira de Ciência do Solo, Campinas, v.21, n.2, p.241-247, 1997.

FONTANELI, R.S.; AMBROSI, I.; SANTOS, H.P. dos; IGNACZAK, J.C.; ZOLDAN, S.M. Análise econômica de sistemas de produção de grãos com pastagens de inverno, em sistema plantio direto. Pesquisa Agropecuária Brasileira, Brasília, v.35, n.11, p.2129-2137, 2000.

FRANCHINI, J.C.; BORKERT, C.M.; FERREIRA, M.M.; GAUDÊNCIO, C.AAlterações na fertilidade do solo em sistemas de rotação de culturas em semeadura direta. Revista Brasileira de Ciência do Solo, Viçosa, v.24, n.2, p.459-467, 2000. 
HERNÁNZ, J.L.; GIRÓN, V.S.; CERISOLA, C. Long-term energy use and economic evaluation of three tillage systems for cereal and legume production in central Spain. Soil \& Tillage Research, Amsterdam, v. 35, n. 4, p.183-198, 1995.

LANGDALE, G.W.; WILSON, R.L.; BRUCE, R.R. Cropping frequencies to sustain long-term conservation tillage systems. Soil Science Society of America Journal, Madison, v.54, n.1, p.193-198, 1990.

LEDINGHAN, R.J. Crop rotations and common root rot in wheat. Canadian Journal of Plant Science, Ottawa, v.41, n.3, p.479-486, 1961.

MATZENAUER, R. Evapotranspiração de plantas cultivadas e coeficientes de cultura. In: BERGAMASCHI, H. et al. Agrometeorologia aplicada à irrigação. Porto Alegre: UFRGS, 1992.Cap.3, p.33-47.

PORTO, V.H da F.Análise econométrica de dados experimentais sobre um sistema de produção trigo-soja, para a cultura de trigo. 1980. 109 f. Dissertação (Mestrado) - ESALQ, USP, Piracicaba.

REIS, E.M.; SANTOS, H.P.; PEREIRA, L.R.Rotação de culturas. IV. Efeito sobre o mosaico e doenças radiculares do trigo em 1983. Fitopatologia Brasileira, Brasília, v.10, n.3, p.637-642, 1985.

RODRIGUES, O.; LHAMBY, J.C.B.; DIDONET, A.D.; MARCHESE, J.A.; SCIPIONI, C. Efeito da deficiência hídrica na produção de trigo. Pesquisa Agropecuária Brasileira, Brasília, v.33, n.6, p.839-846, jun. 1998.

RUEDELL, J. Plantio direto na região de Cruz Alta. Cruz Alta: FUNDACEP FECOTRIGO, 1995.134p.

SANTOS, H.P.; LHAMBY, J.C.B.; PRESTES, A.M.; LIMA, M.R. Efeito de sistemas de manejo de solo e de rotação de culturas de inverno no rendimento e doenças de trigo. Pesquisa Agropecuária Brasileira, Brasília, v.35, n.12, p.2355-2361, 2000.

SANTOS, H.P.; LHAMBY, J.C.B.; PRESTES, A.M.; REIS, E.M.Características agronômicas e controle de doenças radiculares de trigo, em rotação com outras culturas de inverno. Pesquisa Agropecuária Brasileira, Brasília, v.33, n.3, p.277-288, mar. 1998.
SANTOS, H.P.; REIS, E.M.; LHAMBY, J.C.B.; WOBETO, C.Efeito da rotação de culturas sobre o trigo, em sistema plantio direto, em Guarapuava, PR. Pesquisa Agropecuária Brasileira, Brasília, v.31, n.4, p.259-267, 1996.

SANTOS, H.P.; TOMM, G.O. Disponibilidade de nutrientes e teor de matéria orgânica em função de sistemas de cultivo e de manejo de solo. Ciência Rural, Santa Maria, v.33, n.3, p. 477-486, 2003.

SCHAFFENER, E.T.; BREGANTE, C.U. Efecto residual de rastrojos de girasol, maíz, soja y sorgo en el crecimento y producción de trigo. 1984.196p.Dissertação (Mestrado) Facultad de Agronomía, Montevideo.

SLOPE, D.B.; ETHERIDGE, J.; WILLIANS, R.J.B. Grain yield and incidence of take-all and eyespot in winter wheat grown in different crop sequences at Saxmundham. Harpenden, 1973. Part. 2, p.160-167. (Rothamsted Report for 1972)

STATISTICAL ANALYSIS SYSTEMS INSTITUTE. SAS, system for Microsoft Windows, version 8.2. Cary, 2003.

STONE, L.F.; SILVEIRA, P.M. Efeito do sistema de preparo e da rotação de culturas na porosidade e densidade do solo. Revista Brasileira de Ciência do Solo, Viçosa, v.25, n.2, p395401, 2001.

STRECK, E.V.; KÄMPF, N.; DALMOLIN, R.S.D.; KLANT, E.; NASCIMENTO, P.C.; SCHNEIDER, P. Solos do Rio Grande do Sul. Porto Alegre: EMATER, RS/Universidade Federal do Rio Grande do Sul, 2002. 126p.

STURZ, A.V.; BERNIER, C.C. Influence of crop rotations on winter wheat growth and yield in relation to the dynamics of pathogenic crown and root rot fungal complexes. Canadian Journal of Plant Pathology, Guelph, v.11, n.1, p.114-121. 1989. 